\title{
Nombre individuales y colectivos: una propuesta de definición basada en pruebas sintácticas ${ }^{1}$
}

\author{
ÁLVARO GARCÍA MESEGUER
}

CSIC

\section{INTRODUCCIÓN}

La distinción entre nombres individuales y nombres colectivos viene de muy antiguo, pero hasta ahora no se ha dado una definición rigurosa de ambos tipos de nombres.

En efecto, en el pasado distintos gramáticos han pretendido definir el nombre colectivo atendiendo únicamente a su significado, criterio que funciona en algunos casos pero no en muchos otros. Así por ejemplo, nadie duda de que rebaño, familia y yeguada son nombres colectivos; pero ¿qué sucede con palabras como libro y dentadura cuyos referentes son conjuntos de cosas (de hojas y de dientes, respectivamente)? ¿No es una pared un conjunto de ladrillos? ¿Diremos por ello que pared es nombre colectivo? Si una escalera es un conjunto de escalones, ¿es escalera un nombre colectivo? ¿Y qué decir de trenza, que el diccionario define como conjunto de tres ramales entretejidos que se cruzan alternativamente?

Modernamente se ha comprobado que el criterio semántico por sí solo (es decir, el que atiende al significado) no es válido y que para definir los nombres colectivos hay que aplicar algún criterio sintáctico (es decir, qué combinaciones admiten unas palabras con otras).

A partir de ahí se han hecho muchas observaciones dispersas y se han realizado estudios tan profundos y detallados como el de Solé Solé (2002) pero nadie hasta ahora, que sepamos, ha propuesto una definición rigurosa de nombre colectivo (ni de nombre individual, ya que serán individuales todos los nombres que no sean colectivos).

La propuesta que a continuación se expone combina la semántica con la sintaxis y deriva de una reflexión hecha a partir de Bosque (1999 y 2004), habida cuenta del precedente de García Meseguer (1993).

\section{TERMINOLOGÍA INICIAL}

$\mathrm{Si}$, en el mundo físico, nos fijamos en conjuntos tales como una familia, un rebaño, etc. y los comparamos con otros tipos de conjuntos tales como la arena, la nieve o la paja, podríamos decir que los primeros son conjuntos heterogéneos, ya que cada miembro de una familia y cada oveja tiene personalidad propia, distinta de la de los demás; a diferencia de lo que sucede con la arena, la nieve o la paja, cuyos pequeños componentes son homogéneos, es decir, prácticamente idénticos entre sí.

\footnotetext{
${ }^{1}$ Quiero expresar mi profundo agradecimiento al profesor Ignacio Bosque, sin cuyos consejos y asistencia continua -suministrándome bibliografía y revisando mis sucesivos manuscritos- este artículo no existiría. Debo también reconocimiento a los profesores Victoria Escandell, José Antonio Pascual y Rafael García por la acogida mostrada a este trabajo y las ayudas de diversa índole que me han prestado. 
Basados en esta idea, llamaremos nombres heterogéneos a los que designan grupos del estilo de los citados en primer lugar, como es el caso de familia, rebaño, ejército, etc. (su definición rigurosa se da en el § 4). Y llamaremos nombres homogéneos a los que designan grupos del estilo de los citados en segundo lugar, como es el caso de arena, nieve, paja, etc. (su definición rigurosa se da también en el $\S 4$; como veremos, muchos nombres continuos o de materia, pero no todos, pertenecen a este grupo).

Por otro lado y como ya apuntábamos en García Meseguer (1993), necesitaremos distinguir entre nombres compactos y porosos, según que, en singular, rechacen o acepten, respectivamente, la preposición entre. Ahora bien, al usar esta preposición deben tenerse en cuenta las dos peculiaridades siguientes:

- La prueba de si un nombre en singular acepta o rechaza entre debe hacerse en ausencia de coordinación, ya que si hay coordinación todos los nombres en singular aceptan entre, como puede verse en las oraciones entre la puerta y la cama hay una mesilla, entre la casa y el río hay varios árboles, etc.

- Deben tenerse en cuenta los diversos valores que puede tener la preposición entre, circunstancia ésta que merece ser analizada con mayor detalle.

\section{DiVERSOS VALORES DE LA PREPOSICIÓN ENTRE}

Las gramáticas tradicionales del español han apuntado diversos valores semánticos de entre, algunos de los cuales son ejemplificados así en González Rodríguez (2001):

(1) Juan encontró las llaves entre los asientos del coche

(2) Entre Sergio y Lucía organizaron todas las fiestas

(3) Emma y Cristina siempre comentan las noticias entre ellas

(4) Los invitados eran ochenta personas entre familiares y amigos

Se indica allí que en (1) entre hace referencia a un lugar y, en consecuencia, tiene valor locativo, mientras que en (2) entre tiene un valor de cooperación, en (3) un valor recíproco y en (4) un valor que podríamos denominar sumatorio.

Hasta aquí lo dicho en González Rodríguez. Por nuestra parte, nos interesa destacar otro aspecto de la cuestión. Consideremos las oraciones

(5) a. Entre aquellos árboles aparece uno muy frondoso

b. Entre aquellos árboles aparece un mono de vez en cuando

En ambas oraciones la preposición entre incide sobre el plural árboles pero con resultado muy diferente de uno a otro caso. En efecto, en (5a) entre apunta a todos los elementos del conjunto (en este caso, árboles), de los cuales se selecciona uno; en cambio, en (5b) entre apunta a los huecos o espacios que hay entre los elementos del conjunto, por algunos de los cuales aparece algo (un mono) que no pertenece a los elementos del conjunto. Es claro, pues, que el sintagma entre aquellos árboles tiene un significado diferente en (5a) que en (5b), cosa que puede comprobarse fácilmente si comparamos las oraciones de (5) con las de (6), de significado idéntico:

(6) a. Hay un árbol muy frondoso entre aquellos árboles

b. Por los huecos que dejan aquellos árboles entre sí aparece un mono de vez en cuando 
Obsérvese que esta misma distinción puede hacerse en los ejemplos (1) a (4) sacados de González Rodríguez (2001). En efecto, en (1) entre apunta al hueco o espacio entre dos o más elementos (en este caso, los asientos del coche), mientras que en (2), (3) y (4) entre apunta a los elementos mismos del conjunto, que son dos personas en (2) y (3) y ochenta personas en (4).

Las oraciones (5) y (6) están construidas a partir de un nombre en plural (árboles). Oraciones análogas pueden construirse a partir de un nombre colectivo en singular:

(7) a. Entre la documentación intervenida apareció una carta manuscrita

b. Entre la documentación intervenida apareció una cucaracha

(8) a. Entre la chatarra podía verse una lavadora antigua casi nueva

b. Entre la chatarra podía verse una enorme rata corriendo

En (7a) y (8a), análogamente a lo que sucedía en (6a), la preposición entre apunta a todos los elementos del conjunto, constituido, respectivamente, por la documentación intervenida y por la chatarra; mientras que en (7b) y (8b) entre apunta a los huecos o espacios que hay entre esos elementos. Dicho de otro modo: carta y lavadora son elementos que pertenecen, respectivamente, a los conjuntos documentación y chatarra, mientras que cucaracha y rata son elementos ajenos a tales conjuntos.

De lo anterior se deduce que hay dos valores posibles de la preposición entre cuando antecede a un nombre colectivo, según que apunte a las entidades mismas, como en las oraciones (7a) y (8a), o a los huecos que hay entre esas entidades, como en las oraciones (7b) y (8b).

Para distinguir ambos casos, en adelante usaremos la siguiente notación convencional:

entre $_{e}$ cuando apunte a las entidades (oraciones 5a, 7a y 8a)

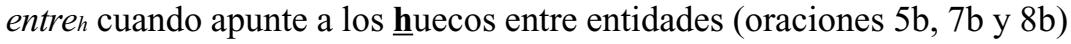

Obsérvese que puede darse cualquier comportamiento de un nombre colectivo frente a estas dos clases de entre. En efecto:

a) Algunos nombres colectivos (tales como documentación, chatarra) admiten ambos valores de entre como hemos visto en los ejemplos citados más arriba. En el mismo caso se encuentra público:

(9) a. Entre el público había un premio Nóbel

b. Entre ${ }_{h}$ el público se perseguían dos perros

b) Otros nombres colectivos (como ejército, patrimonio) admiten entre $e$ y rechazan entre , co- $^{-}$ mo podemos ver en los siguientes ejemplos:

(10) a. Se extiende el malestar entre el ejército

b. *Un terrorista se infiltró entre el ejército

(11) a. Cuenta entre su patrimonio con dos enormes fincas

b. *Desde ayer hay una nueva propiedad entre su patrimonio

En (10a), como el malestar corresponde a las personas, hay que entender que el malestar se extiende entre los elementos que componen el ejército y no entre los huecos que pueda haber entre ellos; por tanto, se trata aquí de entre $e$. En cambio, en (10b) se entiende que el terrorista ocuparía uno de los huecos que hay entre el ejército (puesto que él no forma parte del 
propio ejército), por lo que deducimos que se trata aquí de entreh; pero esta oración no es gramatical, ya que se diría se infiltró en el ejército y no entre el ejército.

En (11a), como las dos enormes fincas pertenecen a su patrimonio, es claro que aquí se

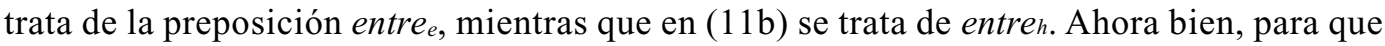
(11b) fuese una oración bien formada habría que decir en su patrimonio y no entre su patrimonio. Queda así visto, por tanto, que ejército y patrimonio aceptan entre e y rechazan entreh.

c) Al contrario del caso anterior, otros nombres colectivos (como arena, gente) admiten entre y rechazan entre :

(12) a. La sortija apareció entre $h$ la arena

b. *Entre la arena $a_{e}$ un grano destaca de los demás

(13) a. La comitiva se abrió paso entre $h$ la gente

b. En (*entre) la gente existe la idea de que fumar no es tan malo

d) En fin, otros nombres colectivos (y por supuesto, todos los nombres individuales: no es posible decir entre la casa, entre el lápiz) rechazan las dos clases de entre, como es el caso de cuadra, nómina. En efecto, ante la oración bien formada

(14) El marqués poseía una numerosa cuadra

deducimos que cuadra en esta acepción es nombre colectivo, ya que admite el adjetivo numeroso. Sin embargo, las oraciones

(15) a. *Entre la cuadra del marqués destaca una yegua muy veloz

b. *Entre la cuadra del marqués corre un gato

están ambas mal formadas por decir entre la cuadra en vez de en la cuadra.

Lo mismo puede decirse del sustantivo nómina, que es colectivo por admitir numerosa y que rechaza las dos clases de entre:

(16) a. La nómina de mi empresa es muy numerosa

b. En (*entre $e_{e}$ ) la nómina de mi empresa figura también mi primo

c. En $(*$ entre $h)$ la nómina de mi empresa se colaron los nombres de dos clientes

Digamos para terminar que todo nombre que acepta entre ${ }_{h}$ es un nombre colectivo que puede denominarse nombre poroso, ya que estos nombres designan grupos cuyos componentes no están íntimamente unidos entre sí, sino que presentan huecos entre esos componentes; y por ello es posible construir sintagmas del estilo de entre la paja, entre el barro, entre la arbole$d a$, etc. Por el contrario, todo nombre que rechaza entre ${ }_{h}$ es un nombre compacto, ya que no hay huecos entre sus componentes: *entre la ganadería, *entre el parlamento, *entre la secta.

\section{DEFINICIÓN DE NOMBRES HETEROGÉNEOS Y NOMBRES HOMOGÉNEOS}

Como dijimos en el $\S 2$, llamaremos nombres heterogéneos a los que en singular designan un conjunto de entidades diferentes entre sí que forman grupo. Ahora los definimos de forma rigurosa del siguiente modo: 


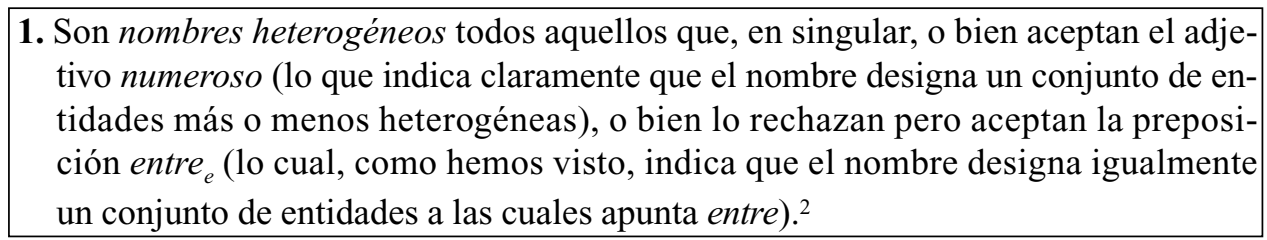

Así por ejemplo, familia y ejército son ambos colectivos heterogéneos por aceptar $n u$ meroso (una familia numerosa, un numeroso ejército); también son colectivos heterogéneos utilería y profesión, ya que, si bien ambos rechazan numeroso, ambos aceptan entre e como muestran los ejemplos siguientes:

(17) a. *Este teatro tiene una numerosa utilería

b. Entre $e$ la utilería de este teatro destaca un sillón estilo Luis XV

(18) a. *Una numerosa profesión

b. Es un periodista muy querido entre $e_{e}$ la profesión

De forma complementaria a la definición 1, llamaremos nombres homogéneos a los que en singular designan un conjunto de entidades muy parecidas entre sí que forman grupo. Ahora los definimos de forma rigurosa del siguiente modo:

2. Son nombres homogéneos todos aquellos que, en singular, rechazan el adjetivo $n u$ meroso y la preposición entre e.

Fácilmente se comprueba que todos los nombres individuales (como libro) son homogéneos, como también son homogéneos un buen número de nombres colectivos, entre ellos nombres continuos o de materia como leña, nieve, paja, penumbra. Ejemplos:

(19) a. *Un numeroso libro

b. * Entre $e$ el libro destaca el capítulo 3

c. *Entre $h$ el libro guardé un pétalo de rosa

(20) a. *Una numerosa leña (nieve, paja)

b. *Entre $e$ la leña (nieve, paja) destaca un cierto leño (copo, brizna)

c. Encontraron el pendiente entre $h$ la leña (nieve, paja)

(21) a. *Una numerosa penumbra

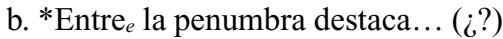

c. Una silueta se dibujó entre $h$ la penumbra del jardín

\section{NOMBRES HETEROGÉNEOS POROSOS Y COMPACTOS}

Hay dos clases de nombres heterogéneos, porosos y compactos. Como ya dijimos, llamaremos heterogéneos porosos a los que designan grupos cuyos componentes no están íntimamente unidos entre sí. Ahora los definimos de forma rigurosa del siguiente modo:

${ }^{2}$ En vez del adjetivo numeroso cabría utilizar otros análogos, como nutrido y copioso, según me indica Ignacio Bosque. Pero ambos adjetivos, así como abundante, además de seleccionar nombres colectivos seleccionan también nombres individuales, por lo que no resultan válidos. Véase al respecto el $\S 12.2$. 
3. Son nombres heterogéneos porosos todos los nombres heterogéneos que en singular aceptan la preposición entre ${ }_{h}$.

Así por ejemplo, utilería, que es un nombre heterogéneo como hemos visto en (17b), es también poroso, ya que cabe decir entre la utilería encontraron un gato muerto, oración en la que entre tiene el valor entreh.

Otros nombres heterogéneos porosos son flota, multitud, cubertería. Véase:

(22) a. Una numerosa flota

b. El acorazado se infiltró entre $h$ la flota enemiga

(23) a. Una numerosa multitud

b. Desapareció entre $h$ la multitud

(24) a. Una numerosa cubertería

b. Guardaba un lápiz de plata entre ${ }_{h}$ la cubertería

De forma complementaria a la definición 3 llamaremos heterogéneos compactos a los que designan grupos cuyos componentes están íntimamente unidos entre sí. Ahora los definimos de forma rigurosa del siguiente modo:

4. Son nombres heterogéneos compactos todos los nombres heterogéneos que, en singular, rechazan la preposición entre . $^{\text {. }}$.

Así por ejemplo, profesión, que es un nombre heterogéneo como hemos visto en (18b), es también compacto, ya que no es gramatical una oración como *un policía se infiltró entre la profesión (sí sería gramatical en la profesión), oración en la que entre tiene el valor entre ${ }_{h}$. Véase:

Otros ejemplos de nombres heterogéneos compactos son tertulia, asamblea, escapada.

(25) a. Una numerosa tertulia (asamblea, escapada)

b. *Un conejo correteaba entre ${ }_{h}$ la tertulia (asamblea, escapada)

\section{NOMBRES HOMOGÉNEOS POROSOS Y COMPACTOS}

De forma análoga a lo dicho para los nombres heterogéneos, hay dos clases de nombres homogéneos, porosos y compactos. Llamaremos homogéneos porosos a los que designan entes constituidos por partículas que dejan huecos entre sí. Ahora los definimos de forma rigurosa del siguiente modo:

5. Son nombres homogéneos porosos todos los nombres homogéneos que, en singular, aceptan la preposición entre ${ }_{h}$.

Son ejemplos de esta clase de nombres los sustantivos barro, trigo, algarabía. Véase:

(26) a. *Un numeroso (barro, trigo)

b. *Entre el (barro, trigo) destaca... (¿?)

c. La moneda estaba oculta entre ${ }_{h}$ el (barro, trigo) 
(27) a. *Una numerosa algarabía

b. *Entre e la algarabía destaca... ( $i$ ?)

c. Entre $h$ la algarabía se oyó un grito de dolor

De forma complementaria a la definición 5 llamaremos homogéneos compactos a los que designan entes constituidos por partículas que no dejan huecos entre sí. Ahora los definimos de forma rigurosa del siguiente modo:

6. Son nombres homogéneos compactos todos los nombres homogéneos que, en singular, rechazan la preposición entre ${ }_{h}$. Ahora bien, como todo nombre homogéneo rechaza entre $e_{e}$ según dijimos en la definición 2 , resulta que los nombres homogéneos compactos se reconocen porque rechazan entre cualquiera que sea su valor.

Los siguientes sintagmas mal formados demuestran que los sustantivos escalera, dentadura, bosque y campanario son homogéneos compactos (es decir, son individuales, como enseguida veremos).

(28) a. *Una numerosa (escalera, dentadura)

b. *Entre la (escalera, dentadura)

(29) a. *Un numeroso bosque (campanario)

b. *Entre el bosque (campanario) ${ }^{3}$

\section{DEFINICIÓN DE NOMBRES COLECTIVOS Y DE NOMBRES INDIVIDUALES}

Todos los nombres heterogéneos (porosos y compactos) más los nombres homogéneos porosos constituyen el conjunto de nombres colectivos. En cuanto a los nombres homogéneos compactos, son falsos colectivos y constituyen el conjunto de nombres individuales. De lo cual se deducen las siguientes definiciones sencillas:

7. Son nombres colectivos los que en singular (y en ausencia de coordinación) aceptan el adjetivo numeroso y/o la preposición entre.

8. Son nombres individuales todos los demás, es decir, los que en singular rechazan el adjetivo numeroso y la preposición entre.

Merece la pena observar, recordando lo que dijimos en el primer párrafo del $\S 2$, que en el mundo físico los entes designados por lo que aquí estamos denominando nombres heterogéneos son conjuntos de entidades con personalidad propia (una familia, un rebaño), mientras que los designados por nombres homogéneos tienen componentes minúsculos y prácticamente idénticos entre sí. Si esos componentes dejan huecos entre ellos (el barro, la nieve, el humo) el resultado será un conjunto de pequeños individuos separados entre sí, es decir, un colectivo; pero si no dejan huecos (el agua, la sangre, el aire) el conjunto de pequeños individuos, al estar soldados entre sí, formará un solo individuo. Esta observación apoya, con toda lógica, el hecho gramatical de que nombres como barro, nieve y humo sean denominados colectivos homogéne-

${ }^{3}$ Más ejemplos de nombres individuales pueden verse en el $\S 12.5$. 
os porosos, y nombres como agua, sangre, aire sean denominados colectivos homogéneos compactos o bien nombres individuales, por ser ambas denominaciones una misma e idéntica cosa.

En la tabla 1 se analizan los ocho casos que resultan al combinar, de todas las formas posibles entre sí, las tres pruebas sintácticas basadas en numeroso, entre y entreh, que son relevantes en la tarea de definir con rigor las diferentes clases de nombres que venimos comentando. El signo + significa que aceptan y el signo - que rechazan. Se ofrecen también algunos ejemplos explicativos.

Tabla $1^{4}$

\begin{tabular}{|c|c|c|c|c|}
\hline Caso & numeroso & entre $_{e}$ & entre $_{h}$ & Clase de colectivo y ejemplos \\
\hline 1 & + & + & + & $\begin{array}{c}\text { Heterogéneo poroso } \\
\text { documentación (30), alumnado, flota }\end{array}$ \\
\hline 2 & + & + & - & $\begin{array}{c}\text { Heterogéneo compacto } \\
\text { ejército (31), clero, bibliografía }\end{array}$ \\
\hline 3 & + & - & + & $\begin{array}{c}\text { Heterogéneo poroso } \\
\text { caravana (32), talonario, baraja }\end{array}$ \\
\hline 4 & + & - & - & $\begin{array}{c}\text { Heterogéneo compacto } \\
\text { convención (33), representación }\end{array}$ \\
\hline 5 & - & + & + & $\begin{array}{r}\text { Heterogéneo poroso } \\
\text { pasaje (34), peonaje }\end{array}$ \\
\hline 6 & - & + & - & $\begin{array}{r}\text { Heterogéneo compacto } \\
\text { juventud (35), herencia, familia }\end{array}$ \\
\hline 7 & - & - & + & $\begin{array}{c}\text { Homogéneo poroso } \\
\text { escombro (36), maleza, tumulto }\end{array}$ \\
\hline 8 & - & - & - & $\begin{array}{r}\text { Homogéneo compacto } \\
\text { falso colectivo }=\text { Individual) } \\
\text { vejez (37), botonadura, goleada }\end{array}$ \\
\hline
\end{tabular}

(30) a. La policía requisó una numerosa documentación

b. Entre la documentación requisada había una lista de nombres

c. Entre la documentación requisada había también dos láminas de goma 2

(31) a. Ese país tiene un ejército muy numeroso

b. Hay mucho malestar entre el ejército

c. Se infiltró un terrorista en (*entre) el ejército

(32) a. Una numerosa caravana de coches apareció en la lejanía

b. En (*entre) la caravana de coches destacaba un mercedes blanco

c. Una veloz moto se introdujo entre la caravana de coches

(33) a. Se celebró una convención muy numerosa

b. En (*entre) la convención sobresalió el delegado de Florida

c. En (*entre) la convención se coló un ladronzuelo

(34) a. *Había un numeroso pasaje

b. Entre el pasaje figuraba un fakir indio

c. El asesino desapareció entre el pasaje

${ }^{4}$ Algunos de los nombres aquí reseñados son de clasificación dudosa, pues la gramaticalidad de los correspondientes sintagmas puede ser discutible. Pero ello no afecta a la validez del método propuesto ni a la existencia de los ocho grupos indicados. 
(35) a. *Una numerosa juventud se congregó en la plaza

b. Entre la juventud cundía el descontento

c. *El ladrón desapareció entre la juventud

(36) a. *Un numeroso escombro

b. En (*entre) el escombro había medio ladrillo de color rojo

c. Varias ratas correteaban entre el escombro

(37) a. *Una numerosa vejez se congregó en la plaza

b. *Entre la vejez cundía el descontento

c. *El ladrón desapareció entre la vejez

\section{CÓMO SE CLASIFICA UN NOMBRE}

Vaya por delante que individual y colectivo son términos excluyentes, es decir, un no colectivo es un individual y un no individual es un colectivo.

Para clasificar un nombre como individual o colectivo, y para conocer, caso de ser colectivo, la clase de colectivo de que se trata, conviene seguir los pasos siguientes:

(1) Si el nombre en singular rechaza numeroso se hace la prueba con entre. Si también rechaza entre se trata de un nombre individual. ${ }^{5}$ Si no se está en este caso, se trata de un nombre colectivo. Si se desea conocer la clase de colectivo, se procede como sigue.

(2) Si el nombre en singular acepta numeroso se trata de un colectivo heterogéneo y debe hacerse la prueba con entreh. Si acepta entreh, es un heterogéneo poroso (caso de ganado, gente, muchedumbre, etc.) y si rechaza entre ${ }_{h}$ es un heterogéneo compacto (caso de familia, cofradia, casuística, etc.).

(3) Finalmente, si el nombre en singular rechaza numeroso pero admite entre, deben tenerse en cuenta los dos valores posibles de entre. Si admite entre y rechaza entre $e_{\text {se }}$ trata de un colectivo heterogéneo compacto (caso de ciudadanía, matrimonio, pareja, etc.); si admite ambos valores de entre se trata de un colectivo heterogéneo poroso (es un caso poco frecuente, al que pertenecen pasaje, utilería); y si rechaza entre (en cuyo caso es claro que admite entreh) se trata de un colectivo homogéneo poroso (caso de barba, fuego, niebla, caos, etc.).

En la figura 1 se ha representado un diagrama de flujo que resume los pasos que acabamos de indicar, necesarios para clasificar un nombre como individual, colectivo homogéneo poroso, colectivo heterogéneo poroso o colectivo heterogéneo compacto.

\section{NOMBRES CONTABLES/NO CONTABLES Y NOMBRES COLECTIVOS}

\subsection{OBSERVACIÓN PREVIA}

\subsubsection{Introducción}

Antes de abordar las relaciones entre nombres contables/no contables y nombres colectivos, debemos hacer algunas consideraciones de carácter general.

En primer lugar, conviene que precisemos que hay cuatro clases de nombres. Las dos primeras son bien conocidas:

9. Son nombres discretos o contables los que en plural aceptan la cuantificación o aposición de numerales y, además, en singular rechazan la graduación o aposición de cuantificadores imprecisos del estilo de mucho, bastante, poco. Ejemplos: águila, crisantemo, jueves, lápiz, mesa, primavera. 
10. Son nombres continuos o de materia los que en singular aceptan la graduación o
aposición de cuantificadores imprecisos del estilo de mucho, bastante, poco y,
además, en plural rechazan la cuantificación o aposición de numerales.
Ejemplos: mármol, mercurio, paz, sangre, serenidad, simpatía.

La gramática tradicional denomina con el nombre de recategorización el hecho de que un nombre habitualmente utilizado por los hablantes como discreto se utilice como continuo (contraste entre he comprado tres jamones y he comido mucho jamón) y viceversa (contraste entre he bebido mucha cerveza y he bebido tres cervezas). Por nuestra parte, en primera aproximación, supondremos que este tipo de sustantivos (jamón, cerveza, etc.) constituyen una tercera clase que denominamos nombres discreto-continuos, cuya definición, junto con la de la cuarta clase de nombres (nombres borrosos), incluimos a continuación.

11. Son nombres discreto-continuos los que en plural aceptan la cuantificación o
aposición de numerales y, además, en singular aceptan la graduación o aposición
de cuantificadores imprecisos del estilo de mucho, bastante, poco. Ejemplos: cer-
do, ensalada, jamón, merluza, pelo.
12. Son nombres borrosos (García Meseguer 1993) los que en plural rechazan la
cuantificación o aposición de numerales y, además, en singular rechazan la gra-
duación o aposición de cuantificadores imprecisos del estilo de mucho, bastante,
poco. Ejemplos: carnicería, chusma, holganza, plebe, pretensión, vejez.

Valga esta exposición detallada para salir al paso de quienes, equivocadamente, identifican continuo con no contable.

A partir de aquí se abren dos caminos diferentes según la forma en que tratemos de dar cuenta del fenómeno denominado recategorización. ${ }^{6}$

\subsubsection{Primera hipótesis: dos clases de nombres discreto-continuos}

En las secuencias:

(38) a. Ayer me compré tres panes

b. Me queda poco pan

(39) a. Ayer me arranqué tres pelos

b. Me queda poco pelo

los sustantivos pan y pelo funcionan como contables en (a) y como continuos en (b), lo que podría llevarnos a la conclusión de que pertenecen a la misma clase; pero basta con acudir al diccionario para darnos cuenta de que se trata, en realidad, de dos casos diferentes. He aquí las definiciones que da el $D R A E-1992$ de ambas palabras:

${ }^{5}$ Para los casos de duda, véase más adelante el $\S 12.1$.

${ }^{6}$ Para Copestake y Briscoe (1995) la recategorización es un caso particular de lo que ellos denominan «polisemia por extensión o cambio de sentido», a diferencia de la «polisemia por modulación de sentido» en la que el sentido del término no cambia sino que se hace más específico de acuerdo con el contexto, como es el caso de la palabra carrete que, según el contexto, significa un carrete de hilo, un carrete de película fotográfica, un carrete de caña de pescar, etc. 


\begin{abstract}
pan. [...] Porción de masa de harina y agua que se cuece en un horno y sirve de alimento, entendiéndose que es de trigo cuando no se expresa otro grano. Puede tener varias formas que toman nombres especiales, pero se llama pan a la pieza grande, redonda y achatada.

pelo. [...] Filamento cilíndrico, sutil, de naturaleza córnea, que nace y crece entre los poros de la piel de casi todos los mamíferos y de algunos otros animales de distinta clase. $\|$ 2. Conjunto de estos filamentos.
\end{abstract}

Como puede observarse, la definición de pan incluye a un tiempo su aspecto de nombre continuo (porción de masa...) y su aspecto de nombre contable o discreto (pieza grande, redonda y achatada), mientras que en el caso de pelo ambos aspectos corresponden a dos acepciones diferentes de la misma palabra. Conviene observar, además, que el plural pelos corresponde únicamente a la primera acepción de la palabra, lo cual significa que la segunda acepción (la de pelo nombre continuo) no tiene plural, es palabra sólo singular (singularia tantum).

Hay que distinguir, pues, el caso de pan del caso de pelo.

- En el primer caso se trata de nombres discreto-continuos, clase a la que pertenecen, además de pan, nombres como ensalada, pollo, merluza, cosecha, error, veneno (individuales) y familia, vajilla, población (colectivos), ya que todos ellos son, a la vez, contables y continuos (comieron cuatro ensaladas y queda mucha ensalada; se reunieron cuatro familias y tengo mucha familia; etc.).

- En el segundo caso se trata de dos acepciones de la misma palabra, una de las cuales es nombre discreto y la otra nombre continuo. En este caso resulta obligado distinguir ambas acepciones con los subíndices 1 y 2 ; así lo hacemos más adelante $(\S 12.5)$ con cabello, café, cascote, grano, paja, pelo, piel y uva, todos ellos análogos a pelo. En su acepción 1 de sustantivos discretos estos nombres son individuales y, como ya hemos dicho, tienen singular y plural; mientras que en su acepción 2 de sustantivos continuos estos nombres son colectivos y no tienen plural, son singularia tantum (solo singular).

\title{
9.1.3. Segunda hipótesis: una sola clase de nombres discreto-continuos
}

Hay otra forma de dar cuenta de la diferencia que existe entre los nombres del primer caso (tipo pan) y los del segundo (tipo pelo). Consiste en suponer que todos los nombres discreto-continuos pertenecen al segundo caso, es decir, que hay una única clase que es la ejemplificada por pelo; o dicho de otro modo, que todos los nombres discreto-continuos tienen dos acepciones y lo que sucede es que los nombres del primer caso, tipo pan, están defectuosamente definidos en el $D R A E$-1992 puesto que, o les falta una acepción, o mezclan entre sí dos acepciones diferentes.

En esta hipótesis, la definición de pan se desdobla en dos, una como nombre continuo y otra como nombre discreto. Véase:

pan. Masa de harina y agua que se cuece en un horno y sirve de alimento, entendiéndose que es de trigo cuando no se expresa otro grano. || 2. Pieza formada con dicha masa; puede tener varias formas que toman nombres especiales, pero se llama pan a la pieza grande, redonda y achatada.

Caso parecido al de pan aunque no idéntico es el de papel, que el DRAE-2001 define en su acepción de nombre discreto en un largo párrafo que, cambiado de orden y dividido en dos partes, resolvería fácilmente el problema, al ser en su primera acepción nombre continuo y en la segunda nombre discreto. Véase: 
papel. [...] Hoja delgada hecha con pasta de fibras vegetales obtenidas de trapos, madera, paja, etc., molidas, blanqueadas y desleídas en agua, que se hace secar y endurecer por procedimientos especiales.

papel (propuesta). Pasta de fibras vegetales obtenidas de trapos, madera, paja, etc., molidas, blanqueadas y desleídas en agua, que se hace secar y endurecer por procedimientos especiales. ॥ 2.- Hoja delgada hecha con dicha pasta.

Otros casos análogos son los de pollo, pato, pavo, merluza, etc., a todos los cuales les falta una acepción. En efecto, el $D R A E-2001$ los define como nombres discretos y omite su acepción de nombre continuo, que añadimos a continuación por nuestra cuenta en letra negrita:

pollo. [...] Cría que nace de cada huevo [...] $\|$ 2. Carne de pollo

pato. [...] Ave palmípededa [...] $\|$ 2.- Carne de esa ave

pavo. [...] Ave del orden de las [...] $\|$ 2. Carne de esa ave

merluza. $[\ldots]$ Pez teleósteo $[\ldots] \|$ 2. Carne de dicho pez

Casos diferentes pero parecidos son los de ensalada, familia y vajilla. Véase:

ensalada. [...] Hortaliza o conjunto de hortalizas [...] || 2. Cantidad de esas hortalizas ${ }^{7}$

familia. [...] Grupo de personas emparentadas entre sí [...] $\|$ 2.- Cantidad de esas personas ${ }^{8}$ vajilla. $[\ldots]$ Conjunto de platos, fuentes $[\ldots] \|$ 2. Cantidad de esos objetos

Estos ejemplos corresponden al caso de nombres discreto-continuos que el $D R A E-2001$ define únicamente como discretos, pero existe igualmente el caso opuesto, es decir, nombres discreto-continuos que el $D R A E-2001$ define únicamente como continuos. He aquí algunos ejemplos, en los que añadimos por nuestra cuenta la acepción faltante en letra negrita:

vino. [...] Licor alcohólico que se hace... $\|$ 2. Porción o clase de dicho licor ${ }^{9}$

agua. [...] Sustancia cuyas moléculas... $\|$ 2. Porción o clase de dicha sustancia

veneno. [...] Sustancia que incorporada... $\|$ 2. Porción o clase de dicha sustancia

jabón. [...] Pasta que resulta de... || 2.- Pieza formada con dicha pasta

\subsubsection{La mejor opción: una sola clase de nombres discreto-continuos}

Si tenemos en cuenta que el DRAE-2001 define cerdo, ternera y jamón con dos acepciones, una como nombre discreto y otra como nombre continuo:

${ }^{7}$ Obsérvese que he comido tres ensaladas se corresponde con la primera acepción (nombre discreto: he comido tres conjuntos de hortalizas) mientras que he comido poca/mucha ensalada se corresponde con la segunda (nombre continuo: he comido poca/mucha cantidad de hortalizas).

${ }^{8}$ Obsérvese que la expresión se reunieron tres familias se corresponde con la primera acepción (nombre discreto: se reunieron tres grupos de personas emparentadas entre si), mientras que la expresión tengo poca/mucha familia se corresponde con la segunda (nombre continuo: tengo poca/mucha cantidad de personas emparentadas conmigo).

${ }^{9}$ Con el sustantivo porción se cubre el caso en que vino se utiliza en oraciones del estilo no beberé más, ya me he tomado tres vinos; y con el sustantivo clase se cubre el caso en que vino se utiliza en oraciones del estilo he probado tres vinos, un rioja, un burdeos y un chacoli. 
cerdo. [...] Mamífero artiodáctilo.... 2. Carne de este animal. Le han aconsejado comer cerdo ternera. [...] Cría hembra de la vaca $\| \mathbf{2}$. Carne de ternera o de ternero

jamón. [...] Pierna trasera del cerdo... $\|$ 2. Carne de esta pierna

concluiremos que son claramente defectuosas, por incompletas, las definiciones que da el DRAE-2001 para pollo, pato, pavo, merluza, etc. vistas anteriormente, ya que se trata del mismo caso que cerdo, ternera. Por tanto, la hipótesis del $\S 9.1 .2$ que se apoya en el $D R A E$ como autoridad incuestionable, no es la más conveniente. ${ }^{10}$

Parece claro, pues, que la segunda hipótesis es preferible a la primera, lo cual nos conduce a perfeccionar del siguiente modo la definición que dimos anteriormente de nombres discreto-continuos:

13. Son nombres discreto-continuos aquellos que tienen dos o más acepciones, de las cuales al menos una es sustantivo discreto y otra sustantivo continuo. Se definen rigurosamente como aquellos y solo aquellos que cumplen las dos condiciones siguientes:

a) aceptar en plural la cuantificación o aposición de numerales; y

b) aceptar en singular la graduación o aposición de cuantificadores imprecisos del estilo de mucho, bastante, poco.

Ejemplos: amistad, amor, café, cerdo, cosecha, ensalada, familia, interés, jamón, líquido, merluza, pan, papel, pelo, pescado, queso, ternera, tontería, verdad, vino, uva

Por otra parte, debemos rectificar lo que dijimos en el $\S 9.1 .1$. No hay cuatro clases de nombres sino tan solo tres - discretos, continuos y borrosos- puesto que los discreto-continuos no son una clase diferenciada de las dos primeras sino tan solo nombres con dos acepciones diferentes, una de cada clase (ver figura 2).

\subsection{LEXICOGRAFÍA DE NOMBRES DISCRETOS Y CONTINUOS}

Aceptada la segunda hipótesis, disponemos de un eficaz procedimiento para revisar las definiciones de los nombres comunes que figuran en los diccionarios. Todos ellos deben atenerse a las siguientes reglas:

- Para definir un nombre contable o discreto debe emplearse como sustantivo de apoyo otro nombre contable o discreto

- Para definir un nombre de materia o continuo debe emplearse como sustantivo de apoyo otro nombre de materia o continuo

- Los nombres discreto-continuos deben aparecer en los diccionarios con dos acepciones al menos, en una de las cuales el sustantivo de apoyo debe ser un nombre discreto y en la otra un nombre continuo. ${ }^{11}$

A título de ejemplo veamos el caso del sustantivo madera en el DRAE-2001. Puesto que la oración necesito mucha madera es una oración bien formada, es claro que madera es nombre continuo. Sin embargo, el $D R A E-2001$ lo define así:

${ }^{10}$ En un delicioso trabajo de José Antonio Pascual (2003) se muestran abundantes ejemplos de incoherencias en el DRAE.

${ }^{11}$ Como es natural, basta con una sola acepción si el sustantivo de apoyo es también discreto-continuo. 
madera. [...] Parte sólida de los árboles cubierta por la corteza || 2. Pieza de madera labrada que sirve para cualquier obra de carpintería

Estas dos definiciones se apoyan ambas en sustantivos contables (parte sólida y pieza) lo que significa que estamos ante un defecto del $D R A E$-2001. Este defecto puede arreglarse fácilmente cambiando así la primera acepción:

madera. Materia que constituye la parte sólida de los árboles...12

Un caso análogo es el del sustantivo hiedra que el $D R A E-2001$ define con una sola acepción correspondiente a nombre discreto:

hiedra. [...] Planta trepadora siempre verde...

Sin embargo, hiedra es nombre discreto-continuo, ya que las oraciones He plantado tres hiedras y Hay mucha hiedra en esa pared están ambas bien formadas. Por consiguiente, falta una segunda acepción de hiedra como nombre continuo, que podría ser la que escribimos a continuación en negrita:

hiedra. Planta trepadora siempre verde... || 2. Espesura que forma dicha planta

\subsection{Compatibilidad entre clases de nombres comunes}

Las clasificaciones de los nombres en discretos o contables, continuos o de materia y borrosos, por un lado, y en individuales y colectivos, por otro, son independientes entre sí y tratar de encontrar alguna correspondencia entre ellas tiene, a nuestro juicio, muy poco interés. Se trata de criterios clasificatorios diferentes y compatibles entre sí, como se demuestra con los siguientes ejemplos que cubren todos los casos posibles:

1. Nombres discretos individuales: árbol, boda, combate, disparo, eclipse, guerra, locura, mariposa, oficio, promesa, sorpresa, verano

2. Nombres discretos colectivos: alboroto, censo, madeja, melena, orquesta, piara, rebaño, sínodo, tertulia, tribu, vocabulario

3. Nombres continuos individuales: agua, aire, distancia, espacio, gas, madera, mercurio, oxígeno, sangre, tiempo, timidez, tristeza

4. Nombres continuos colectivos: alumnado, barro, basura, maleza, mobiliario, palabrería, polvo, porquería, prole

5. Nombres borrosos individuales: atletismo, blancura, convalecencia, espera, goleada, niñez, rehabilitación

6. Nombres borrosos colectivos: bruma, ciudadanía, cristiandad, chusma, plebe, verdor, viguería

${ }^{12}$ Curiosamente, la tercera acepción de madera en el $D R A E-2001$ sí se apoya en el sustantivo materia. Dice así: «3. Materia de que se compone el casco de las caballerías». 


\section{EL ASPECTO NOMINAL ${ }^{13}$}

\subsection{INTRODUCCIÓN A MODO DE RECORDATORIO}

Si en el mundo físico analizamos el interior de los entes que están en el espacio observaremos que, tal y como dijimos en el § 7, aquellos entes que se designan con nombres heterogéneos son conjuntos de entidades con personalidad propia (una familia, un rebaño), mientras que los designados con nombres homogéneos tienen componentes minúsculos y prácticamente idénticos entre sí (el trigo, la nieve).

Por otra parte, si continuamos analizando el interior de esos mismos entes, podemos observar de qué forma los componentes anteriormente citados se relacionan unos con otros. Si esos componentes están separados entre sí dejarán huecos entre ellos, con lo que el resultado será un ente que hemos denominado nombre poroso; y si no dejan huecos entre sí sino que están soldados unos con otros, el resultado será un ente denominado nombre compacto.

Como ya sabemos, todos los nombres porosos son colectivos, mientras que hay dos clases de nombres compactos. Los compactos heterogéneos son nombres colectivos, puesto que los componentes del ente al cual designan tienen entidad propia; en cambio, los compactos homogéneos son falsos colectivos, ya que en realidad son nombres individuales, al ser los componentes del ente al cual designan pequeñas partículas unidas entre sí.

Para mayor claridad, es oportuno transcribir aquí lo que dijimos en el § 7:

Si esos componentes dejan huecos entre ellos (el barro, la nieve, el humo) el resultado será un conjunto de pequeños individuos separados entre sí, es decir, un colectivo; pero si no dejan huecos (el agua, la sangre, el aire) el conjunto de pequeños individuos, al estar soldados entre sí, formará un solo individuo. Esta observación apoya, con toda lógica, el hecho gramatical de que nombres como barro, nieve y humo sean denominados colectivos homogéneos porosos, y nombres como agua, sangre, aire sean denominados colectivos homogéneos compactos o bien nombres individuales, por ser ambas denominaciones una misma e idéntica cosa.

\subsection{GÉNERO, NÚMERO Y ASPECTO}

De lo anterior se desprende que la clasificación de un nombre como colectivo o como individual es una cuestión de aspecto interior ya que deriva de una observación efectuada en el interior del ente designado, en el cual se analizan sus partículas por una parte y el cómo están de juntas o separadas entre sí por otra.

En cambio, la clasificación de un nombre como discreto o como continuo es una cuestión de aspecto exterior, ya que deriva de una observación efectuada desde el exterior del ente designado. Recordemos que, según el DRAE-2001, discreto significa «separado, distinto» y continuo significa «que se extiende sin interrupción». En efecto, si el ente designado por el nombre se nos aparece junto a otros (de su misma o de otra especie) de un modo separado, distinto, será un ente discreto o contable; y si se nos aparece como un elemento único, que se ex-

${ }^{13}$ Hasta ahora el concepto de aspecto se ha venido aplicando únicamente al aspecto verbal (aktionsart), refiriéndose con ello al aspecto de la acción representada por el verbo. Aquí trataremos de algo análogo pero diferente, a saber: el aspecto nominal, refiriéndonos con ello al aspecto de la cosa representada por el nombre. 
tiende ante nuestra vista sin interrupción alguna, sin contraste con ningún otro, será un ente continuo o de materia. ${ }^{14}$

Por consiguiente, los dos pares de rasgos discreto/continuo, individual/colectivo, son componentes de la categoría gramatical de aspecto nominal, hermana de las dos categorías bien conocidas de género y número.

Sucede que la gramática tradicional trata de manera totalmente independiente al género y número por una parte (bajo el título de la flexión nominal o cosa parecida) y a los nombres discretos, continuos, individuales y colectivos por otra (bajo el título de clases de nombres o cosa parecida), cuando en realidad ambas materias deben englobarse en una sola. Postulamos, en efecto, que existen cuatro categorías gramaticales en el paradigma nominal: el género, el número, el aspecto exterior y el aspecto interior. Las dos primeras son categorías morfológicas, puesto que cualquier hablante del español, con sólo ver el sustantivo aislado, es capaz de conocer su género y su número; ${ }^{15}$ y las dos últimas son categorías sintácticas, puesto que requieren de la sintaxis (el acompañamiento de palabras como cuatro, bastante, numeroso, entre) para manifestarse. Esta diferencia explica que los gramáticos, hasta ahora, no hayan reconocido al aspecto nominal como categoría gramatical con personalidad propia, al no ser ésta una cuestión de morfología (como en el caso del género y del número) sino de sintaxis. ${ }^{16}$

Por otra parte hay que decir que llamar categorías flexivas del nombre al género y el número es un tanto engañoso, porque sugiere que todos los nombres adquieren su género y su número por flexión, lo cual no es cierto. Solamente las palabras de doble forma por género (del estilo de amigo/amiga) o por número (del estilo de mesa/mesas) son formas flexivas. Todas las demás (como artista de género implícito, árbol de género masculino, mesa de género femenino; tesis de número implícito, niñez solo singular y nupcias solo plural) tienen género y número sin que haya flexión, es decir, son todo raíz y, si bien tienen género y número, no tienen morfema de género o de número. ${ }^{17}$

Género, número, aspecto exterior y aspecto interior corren parejos y deben ser tratados en todo momento de forma análoga. Una manera de evidenciar esta analogía sería, por ejemplo, exponer del siguiente modo las diferentes clases de nombres comunes:
14. Los nombres comunes se dividen:
a) según su género, en masculinos y femeninos
b) según su número, en singulares y plurales
c) según su aspecto exterior, en discretos, continuos y borrosos
d) según su aspecto interior, en individuales y colectivos

\footnotetext{
${ }^{14}$ Este tipo de razonamientos -para mí, tan clarificadores- que ligan lengua con realidad no tiene muchos partidarios entre los lingüistas, la mayoría de los cuales prefiere estudiar la lengua como un ente aislado. No es este el caso de Anna Wierzbicka, para quien la sintaxis no es ni «autónoma» ni «arbitraria», sino que deriva en buena medida de la «semántica». Siento el mayor aprecio por sus trabajos, en particular Wierzbicka (1985 y 1988).

${ }^{15}$ Se exceptúan los casos de género y número implícitos, del estilo de artista, testigo para el género y tesis, paréntesis para el número.

${ }^{16}$ En un próximo trabajo sobre nombres abstractos propondremos la existencia de una quinta categoría nominal.

${ }^{17}$ Más detalles al respecto pueden verse en García Meseguer (1989 y 1996).
} 


\section{RELACIONES ENTRE PLURALES Y COLECTIVOS ${ }^{18}$}

Hasta aquí ha quedado muy claro que el concepto de nombre colectivo es algo que se aplica a los nombres en singular; y que para descubrir si un nombre en singular es o no colectivo basta con aplicar la doble prueba sintáctica de entre (en ausencia de coordinación) y numeroso.

Ahora bien, en este apartado vamos a extender el concepto de colectivo a los nombres en plural; y para descubrir si un nombre en plural es o no colectivo aplicaremos la misma prueba sintáctica de entre y numeroso (en este caso, numerosos).

Vaya por delante que todos los nombres con flexión de número (es decir, de doble forma por número) son contables y en su forma de plural son nombres colectivos; y ello es así tanto si se trata de nombres individuales (árbol, mesa) como si se trata de nombres colectivos (familia, rebaño). En efecto, cuando decimos tres árboles, cuatro mesas, dos familias y cinco rebaños estamos aludiendo a conjuntos de tres, cuatro, dos y cinco entidades respectivamente; por lo que árboles, mesas, familias y rebaños resultan ser nombres colectivos. Además, como todos estos nombres admiten el adjetivo numerosos y la preposición entre, se trata de colectivos heterogéneos porosos.

Son también contables y, por tanto, son en plural nombres colectivos, los nombres de número ambiguo (del estilo de tesis, lunes, quitamanchas, etc.), es decir, los nombres que sin cambiar de forma pueden funcionar tanto en singular como en plural; nombres a los cuales preferimos denominar nombres de número implícito ya que no es posible conocer su número cuando aparecen aislados, siendo necesario acudir a la concordancia en cada caso para que ese número se haga explícito. En efecto y análogamente al caso anterior, cuando decimos tres tesis, cuatro lunes, dos quitamanchas, etc. estamos aludiendo a conjuntos de tres, cuatro y dos entidades respectivamente, por lo que tesis, lunes, quitamanchas, resultan ser, cuando actúan en plural, nombres colectivos.

Resuelto así el caso de los plurales contables -que son mayoría-queda por ver qué sucede con los plurales no contables, algunos de los cuales son colectivos y otros no, como más adelante tendremos ocasión de comprobar. Nuestra tarea es, ahora, delimitar en lo posible uno y otro grupo.

Pero antes de seguir adelante conviene precisar el concepto de pluralia tantum. Lo hacemos a continuación.

\subsection{LOS PLURALIA TANTUM}

La gramática tradicional denomina pluralia tantum a los nombres que no tienen singular, pero muchos gramáticos han extendido el concepto a otro tipo de nombres que, teniendo singular, muestran características parecidas a los anteriores.

A título de ejemplo, he aquí lo que dice Bosque (1999: $§ 1.3)$ :

En los apartados anteriores hemos venido asumiendo que los sustantivos pluralizables (libros, años) pertenecen a la misma clase que los sustantivos cuantificables, sea con indefinidos ( $\mathrm{mu}$ chos libros) o con numerales (cuatro años). Así es, efectivamente, en la mayor parte de los casos. Existe, sin embargo, una serie sistemática de excepciones, que se suelen recoger con el tér-

\footnotetext{
${ }^{18} \mathrm{~A}$ la hora de juzgar los ejemplos que aparecen en este apartado debe recordarse la nota 4 anterior.
} 
mino latino pluralia tantum (literalmente 'plurales sólo'). Así, podemos decir de alguien que tiene celos, que guarda las ropas en algún sitio o que no tiene ganas de leer, pero no diríamos que tiene un determinado número de celos, de ganas o de ropas.

De lo anterior se deduce que Bosque considera incluidos en los pluralia tantum a los nombres no contables (no sabemos si a todos ellos o si solamente a algunos) aún cuando tengan singular, como es el caso, en sus ejemplos, de celo, ropa y gana.

Por nuestra parte no seguiremos este criterio, por estimar que resulta más conveniente separar por completo los pluralia tantum de los nombres no contables, al menos en un primer análisis. Por ello, en lo sucesivo consideraremos pluralia tantum únicamente a los sustantivos que no tienen singular.

\subsection{Distintas CLASES DE PLURALES Y SU RELACIÓN CON LOS COLECTIVOS}

Para un estudio ordenado de las relaciones que existen entre plurales y colectivos conviene separar los nombres en distintos grupos. Así lo hacemos a continuación, siguiendo un criterio morfológico.

Grupo A: Constituyen este grupo, muy numeroso, todos aquellos plurales que corresponden a nombres de doble forma por número. Así por ejemplo, sustantivos como libros, mesas, calores, esperanzas, facciones, manias, angarillas, trizas, gajes, alicates pertenecen a este grupo, ya que existen las voces libro, mesa, calor, esperanza, facción, manía, angarilla, triza, gaje y alicate.

En este grupo encontramos palabras de muy diferente naturaleza, por lo que conviene subdividirlo. Así lo hacemos más adelante.

Importa añadir que, como es lógico, las entradas en el diccionario de todos estos nombres del grupo A aparecen únicamente en singular.

Grupo B: Constituyen este grupo todos los nombres que son sólo plurales, llamados pluralia tantum por la gramática tradicional. Así por ejemplo, sustantivos como añicos, creces, nupcias, pertrechos, víveres pertenecen a este grupo, ya que no existen las voces *añico, *crez, *nupcia, *pertrecho, *vivere.

Importa añadir que, a diferencia del caso anterior, las entradas de estas voces en el diccionario aparecen en plural. Recíprocamente, aquellas y solo aquellas voces cuyas entradas aparecen en plural en el diccionario constituyen para nosotros el conjunto de pluralia tantum.

Todos los nombres de este grupo son no cuantificables, ya que no decimos tres añicos, cuatro creces, etc. Por otra parte, la mayoría de estos nombres, tales como albricias, anales, añicos, arras, creces, entendederas, expensas, fastos, tragaderas son individuales, puesto que, como fácilmente puede comprobarse, rechazan el adjetivo numerosos y la preposición entre. El resto de nombres del grupo (que son minoría) aceptan numerosos o entre y son, por ello, colectivos: bártulos, enseres, exequias, nupcias, pertrechos, vituallas, viveres. Véase:

(40) Había numerosos bártulos y entre los bártulos se veían algunos ratones

(41) Entre los muchos enseres de su casa destacan un sofá isabelino, una vihuela y una escopeta de chispa

(42) Este cura ha celebrado numerosas exequias en su vida

(43) Entre las nupcias celebradas aquel año destaca la de los príncipes de España

(44) Trajeron numerosas vituallas (numerosos pertrechos, víveres).

Como, según acabamos de decir, todos los nombres de este grupo son no cuantificables (es decir, no discretos) y, por otra parte, todos ellos son no continuos (mal podrían ser continuos, cuando 
los nombres continuos son de forma única singular y aquí tratamos de nombres de forma única plural), fácilmente concluimos que todos los nombres pluralia tantum son nombres borrosos.

Grupo C: Constituyen este grupo todos los nombres de número ambiguo o implícito (en el sentido de no-explícito; su número devendrá explícito por concordancia con otra palabra), es decir, que pueden funcionar como singular y como plural. Así por ejemplo, sustantivos como tesis, manitas, paréntesis, cirrosis, lunes, martes pertenecen a este grupo, ya que puede decirse una tesis/dos tesis, Pedro es un manitas/Pedro y Juan son dos manitas, etc. También pertenecen a este grupo nombres derivados del estilo de lavacoches, sacacorchos, tocadiscos, quitamanchas, etc. ${ }^{19}$ Todos los nombres de este grupo C son individuales y cuantificables; por consiguiente, sus plurales son colectivos.

Estos tres grupos A, B y C agotan todos los plurales existentes en la lengua, sin que haya ningún solapo entre los grupos. En efecto, todos los nombres de doble forma por número (S y P) están en A; todos los que son solo plural (P) están en B; los que son solo singular (S) no entran en nuestro estudio; y los que pueden ser singular o plural ( $\mathrm{S}$ o P) están en $\mathrm{C}$.

Como hemos visto, en el grupo B hay plurales de las dos clases, individuales y colectivos: $\mathrm{y}$ en el $\mathrm{C}$ todos los plurales son colectivos. En cuanto al grupo A, conviene subdividirlo del siguiente modo.

Grupo A1: Está constituido por los duales léxicos, todos los cuales son ambiguos ${ }^{20}$ (Bosque, 1999), es decir, que pueden funcionar como referidos a una sola entidad o como referidos a varias entidades. Ejemplos: pantalones, tijeras, anteojos, alforjas, angarillas, gafas, esposas, etc. Cabe decir tengo unos pantalones (tijeras, anteojos,... ) y tengo cuatro pantalones (tijeras, anteojos,,..$)$.

Todos los nombres de este grupo son cuantificables; por consiguiente, frente al rasgo individual-colectivo objeto de nuestro análisis se comportan como árbol/árboles, es decir: cuando el nombre se refiere a una sola entidad se trata de un nombre individual, y cuando se refiere a varias entidades se trata de un nombre colectivo.

Grupo A2: Está constituido por todos aquellos nombres de doble forma por número que se utilizan con mucha más frecuencia en plural que en singular, hasta tal punto que muchos autores, como Bosque (1999), incluyen este grupo entre los pluralia tantum. Ejemplos: adentros, afueras, andares, calores, comestibles, entrañas, facciones, ganas, modales, ojeras, restos, sudores, turbas, vituallas.

En este grupo todos los nombres que acabamos de mencionar son individuales, puesto que, además de ser no cuantificables, rechazan numerosos y entre; pero hay también unos pocos que son colectivos (babas, bienes, cimientos, comestibles, manías, posesiones, provisiones, útiles). Véase:

(45) Se le paseaba una mosca entre las babas

(46) Entre sus (bienes, posesiones) figura un palacio antiguo

(47) Encontraron dos perros muertos entre los cimientos

(48) Trajo numerosos/as (comestibles, provisiones)

(49) Entre sus muchas manías está la de bajar escaleras a la pata coja

(50) Entre aquellos útiles de cocina destacaba una enorme rasera.

${ }^{19}$ Ambadiang estudia la estructura de los nombres derivados (1999: $§ 74.3 .3 .3$ ).

${ }^{20}$ No debe confundirse ‘plural ambiguo' con 'nombre de número ambiguo o implícito'. Los plurales ambiguos (tijeras, pantalones) tienen forma en singular (tijera, pantalón) mientras que los nombres de número ambiguo o implícito son de forma única (tesis, lunes). Se trata de dos conjuntos disjuntos, sin elementos comunes. 
Grupo A3: Está constituido por aquellos nombres de doble forma por número que ni son duales léxicos ni se utilizan con más frecuencia en plural, es decir, que no pertenecen al grupo A1 ni al A2. Dentro de este grupo la mayor parte de los plurales son cuantificables. Ejemplos: árboles, casas, libros ... Como ya dijimos, todos estos plurales son colectivos.

Restan los plurales no cuantificables del grupo A3. Algunos de ellos aceptan numerosos o entre, es decir, son colectivos: escombros, ropas, Otros, como ansias, esperanzas, sudores, vanidades, rechazan numerosos y entre, siendo por ello individuales.

\subsection{RESUMEN DE LAS RELACIONES PLURAL-COLECTIVO}

De todo lo anterior se deducen las siguientes relaciones entre plurales y colectivos.

1. Desde el punto de vista morfológico hay cuatro clases de nombres: los que son de doble forma singular-plural (mano-manos, árbol-árboles), los que son solo singular (caos, $n i$ nez), los que son solo plural (fauces, albricias) y los que son de número ambiguo o implícito (tesis, lunes). Por consiguiente, hay tres clases de plurales: los que tienen singular, los que no tienen singular (pluralia tantum) y los que pueden ser singular sin cambiar de forma (nombres de número implícito).

2. Aquellos nombres que, teniendo singular, son cuantificables (como árboles, libros, casas, caballos, etc.) son todos colectivos. Este es el grupo más numeroso y en él se incluye el conjunto de duales léxicos (pantalones, tijeras, anteojos, alforjas, angarillas, gafas, esposas, etc.).

3. Aquellos nombres que, teniendo singular, no son cuantificables, pueden dividirse en dos grupos: los que se usan con mayor frecuencia en plural y los que no se usan con mayor frecuencia en plural. Los primeros son en su mayor parte individuales (afueras, agujetas, andas, arrumacos, celos, dominios, facciones, gajes, ganas, modales, ojeras, represalias, restos, turbas), si bien existen algunos que son colectivos (babas, bienes, cimientos, comestibles, manías, posesiones, provisiones, útiles). Del mismo modo, los segundos son en su mayor parte individuales (ansias, esperanzas, sudores, vanidades) si bien existen algunos que son colectivos (escombros, ropas).

4. Los pluralia tantum son todos no cuantificables. La mayor parte de ellos, tales como albricias, ambages, añicos, arras, creces, entendederas, explicaderas, fastos, manes, penates, son individuales; pero hay algunos otros, como enseres, exequias, nupcias, provisiones, víveres, que son colectivos.

5. Los nombres de número implícito (lunes, jueves, tesis, paréntesis) son todos cuantificables. Por consiguiente, cuando actúan como plurales son todos colectivos.

\section{CONSIDERACIONES FINALES}

\subsection{ACERCA DE LOS NOMBRES INDIVIDUALES}

El método propuesto zanja de una vez por todas cualquier duda que pueda presentarse sobre si un determinado nombre debe clasificarse como individual o como colectivo, términos ambos que son opuestos entre sí, sin resquicios intermedios: individual y no colectivo son rigurosamente sinónimos, al igual que colectivo y no individual. ${ }^{21}$

${ }^{21}$ No contradice lo dicho la existencia de nombres como paja, pelo, uva que pueden actuar como individuales (ver la paja en el ojo ajeno) y como colectivos (lo encontró entre la paja), ya que se trata de dos acepciones distintas $\left(\right.$ paja $_{1}$ y paja $\left._{2}\right)$ de la misma palabra. 
En particular, el método permite clasificar unívocamente muchos nombres inicialmente dudosos, como es el caso, entre otros, de alameda, biblioteca, bosque, botonadura, campanario, catálogo, cordillera, dentadura, empresa, escalera, haz, madeja, melena, pinacote$c a$, puñado, ramo, sarta, y trenza, nombres todos ellos que, por su significado, podrían hacernos pensar que son colectivos. Sin embargo, es fácil comprobar que todos ellos rechazan entre y numeroso, por lo que resultan ser nombres individuales.

En caso de duda sobre si un nombre admite o no numeroso o entre cabe resolver la duda consultando algún corpus del estilo del Corpus de Referencia del Español Contemporáneo (CREA). Como ejemplo puede mencionarse el sustantivo biblioteca, ya que parece dudoso si el sintagma una numerosa biblioteca está bien construido o no. Hecha la consulta en CREA resulta que no hay ninguna cita que contenga ese sintagma, ni tampoco el sintagma entre la biblioteca; sin embargo, en CORDE aparecen las cuatro citas siguientes:

1. «.... que ellos solos compondrían hoy una numerosa biblioteca...» (Leandro Fernández de Moratín: Orígenes del teatro español, 1830)

2. «.... para que en su excelentíssima y numerosa biblioteca se conserven contra el olvido...» (José Pellicer de Ossau Salas y Tovar: Vida de don Luis de Góngora, 1915)

3. «... un edificio magnífico y una escogida y numerosa biblioteca....» (Leandro Fernández de Moratín: Cartas de 1787. Epistolario)

4. «... el calendario de la sala, cromo aburrido entre la biblioteca...» (Juan Ramón Jiménez: Diario de un poeta reciencasado, 1916)

Parece, pues, que biblioteca funcionaba como colectivo hasta hace casi un siglo, pero que hoy día ha pasado a ser individual, razón por la cual se ha preferido clasificarlo aquí como nombre individual. Una vez más se pone de manifiesto que, si bien en muchos casos las palabras tienen un carácter bien definido, en muchos otros no son las palabras en sí mismas las que tienen uno u otro carácter, sino que son los hablantes quienes, según la forma en que las usan, les confieren uno u otro carácter.

\subsection{AdJETIVOS SIMILARES A NUMEROSO}

Además de numeroso, otros posibles candidatos alternativos que podrían utilizarse para definir los nombres colectivos serían adjetivos como nutrido, copioso y abundante, cuyos significados, según el $D R A E-2001$, son los siguientes:

nutrido. [...] Lleno, abundante. Estudio nutrido de ideas. Biografia muy nutrida de datos. copioso. [...] Abundante, numeroso, cuantioso

abundante. [...] Copioso, en gran cantidad

Ahora bien, como puede verse, para el DRAE-2001 los tres son sinónimos y significan cuantioso, en gran cantidad, es decir, no aluden necesariamente a conjuntos; a diferencia de numeroso cuyo significado es que incluye gran número de personas o cosas, lo que apunta claramente a conjuntos.

$\mathrm{Y}$ en efecto, es fácil comprobar que, si bien los tres adjetivos seleccionan algunos nombres colectivos, también seleccionan diversos nombres individuales. He aquí varios ejemplos: ${ }^{22}$ 
Nombres seleccionados por copioso:

Colectivos: bibliografía, correspondencia, fortuna, herencia, manifestación, tráfico

Individuales: beneficio, caudal, documento, flujo, gasto, ingreso, sudor

Nombres seleccionados por nutrido:

Colectivos: asamblea, bibliografia, correspondencia, delegación, elenco, séquito

Individuales: agenda, apoyo, beneficio, cifra, depósito, hucha, literatura

Nombres seleccionados por abundante:

Colectivos: bibliografía, correspondencia, lluvia, obra, oferta, participación

Individuales: actividad, agua, conocimiento, líquido, sudor, trabajo, vino

Por consiguiente, a diferencia de lo que sucede con numeroso, ninguno de los adjetivos nutrido, copioso y abundante puede constituir una prueba sintáctica válida para definir la clase de nombres colectivos, puesto que también seleccionan nombres individuales.

\subsection{LEXICOGRAFÍA DE NOMBRES INDIVIDUALES Y COLECTIVOS}

En el $\S 9.2$ vimos las reglas que deben seguirse a la hora de definir un sustantivo según que sea nombre discreto, nombre continuo o nombre discreto-continuo. Ahora, de forma totalmente análoga, indicaremos unas reglas similares relativas a la definición de un sustantivo según que sea individual o colectivo. ${ }^{23}$

- Al definir un nombre individual debe emplearse como sustantivo de apoyo otro nombre individual

- Al definir un nombre colectivo debe emplearse como sustantivo de apoyo otro nombre colectivo

- Cuando un nombre pueda funcionar como individual y como colectivo, ${ }^{24}$ su definición deberá comprender dos acepciones, una para cada clase de nombre; o bien una acepción única en la que el sustantivo de apoyo pueda funcionar, igualmente, como individual y como colectivo.

A título de ejemplo veremos los casos de trenza, cosecha, selva y archipiélago. El primero se define así en el $D R A E-2001$ :

trenza. [...] Conjunto de tres ramales que se entretejen, cruzándolos alternativamente

Sin embargo, trenza es nombre individual (*una numerosa trenza; *entre la trenza) por lo que no es correcto definirlo como conjunto de, ya que conjunto es nombre colectivo. Más correcto sería decir algo así como «especie de cordón formado por tres ramales que se entretejen, cruzándolos alternativamente». ${ }^{25}$

${ }^{22}$ La concordancia de cada uno de los nombres que figuran en los ejemplos con el adjetivo correspondiente está basada, en el caso de copioso y nutrido, en Bosque (2006); y en el caso de abundante, en el Corpus de Referencia del Español Actual (CREA) de la Real Academia.

${ }^{23}$ Estas reglas, junto con las enunciadas en el $\S 9.2$, suponen una aportación a favor de la coherencia de los diccionarios, coherencia tantas veces predicada como necesaria por José Antonio Pascual (1996).

${ }^{24}$ Estos nombres podrían denominarse individual-colectivos a semejanza de los llamados discreto-continuos; son, en efecto, casos totalmente análogos. Ninguno de ellos constituye una clase nueva de nombres por tratarse, en ambos casos, de nombres con dos acepciones, una de cada clase.

${ }^{25}$ Con buen tino, el $D U E$ define trenza apoyándose en la palabra tejido que es nombre individual. 
El caso de cosecha es más o menos parecido. Se define así en el $D R A E-2001$ :

cosecha. [...] Conjunto de frutos, generalmente de un cultivo, que se recogen de la tierra al llegar a la sazón; como de trigo, cebada, uva, aceituna, etc. ${ }^{26}$

Sin embargo, cosecha es individual, pues no decimos *entre la cosecha ni tampoco * una numerosa cosecha; lo que decimos es una abundante cosecha ${ }^{27}$ y la prueba es que no decimos *Un numeroso conjunto de frutos. Por tanto, el sustantivo conjunto no sirve como apoyo para definir cosecha. ¿Qué sustantivo escogemos?

Lo primero es averiguar si cosecha es nombre discreto o continuo. Decimos con toda naturalidad tanto recogi tres cosechas como recogí mucha cosecha, luego se trata de un nombre discreto-continuo; por tanto, el sustantivo de apoyo ha de ser de la misma clase. Escogemos cantidad, con lo que la definición queda así:

cosecha. Cantidad de frutos, generalmente de un cultivo, que se recogen de la tierra al llegar a la sazón; como de trigo, cebada, uva, aceituna, etc.

Ahora debemos comprobar que cantidad es también nombre discreto-continuo. En efecto, así es, como demuestra la siguiente oración bien formada:

Hice dos pasteles con dos cantidades diferentes de azúcar y resultó que el primero llevaba poca cantidad

Al contrario de lo que sucede con trenza y cosecha, ambos nombres individuales que el $D R A E$-2001 define como colectivos, el DRAE-2001 ofrece para selva una acepción única como nombre individual («Terreno extenso, inculto y muy poblado de árboles»), ignorando que, en una de sus acepciones, selva es nombre colectivo. En efecto, el sintagma entre la selva es perfectamente gramatical, como prueba el hecho de que en CREA aparece este sintagma, sin coordinación con otro nombre, hasta en 14 documentos. Deducimos por ello que falta una acepción en el $D R A E-2001$, que podría ser del estilo de la que reseñamos a continuación en letra negrita:

selva. Terreno extenso, inculto y muy poblado de árboles $\|$ 2. Conjunto de esos árboles.

En cuanto al sustantivo archipiélago, se trata de un nombre individual, al no ser gramaticales las expresiones *un numeroso archipiélago / *entre el archipiélago. Por ello resulta errónea la definición del $D R A E-2001$, que se apoya en el sustantivo conjunto («Conjunto, generalmente numeroso, de islas agrupadas en una superficie más o menos extensa, de mar»). Esa definición mejoraría si se eliminase la palabra conjunto.

Pero hay más. El diccionario de María Moliner define archipiélago como «Cualquier porción de mar poblada de islas» (DUE, s. v.), apoyándose en un nombre individual como debe ser. La diferencia con el $D R A E-2001$ es notoria. ¿Un archipiélago es agua o es tierra? Sin ninguna duda, la respuesta es a favor de agua, ya que la expresión El barco se hundió en el ar-

${ }^{26}$ Aquí yerra también el DUE, al definir cosecha como conjunto de frutos.

${ }^{27}$ Sobre los nombres seleccionados por abundante véase el $\S 12.2$ 
chipiélago de los Chonos, al sur de Chile es claramente gramatical y un barco no puede hundirse en un conjunto de islas..$^{28}$

En definitiva, el $D R A E-2001$ comete dos errores, uno de forma (definir archipiélago como un conjunto) y otro de fondo (confundir unas islas con el mar que las rodea).

\subsection{AlgunAs CURIOSIDADES}

- Lluvia y llovizna son colectivos porosos (Se perdió entre la lluvia / la llovizna)) pero aguacero («lluvia repentina y abundante, de corta duración»), chubasco («aguacero con mucho viento») y chaparrón son individuales (*Se perdió entre el aguacero/el chubasco/el chaparrón). Parece que, al caer muchas gotas muy juntas y en un corto periodo de tiempo, ya no vemos huecos entre ellas sino un todo único, según nos muestra la lengua.

- Juventud es colectivo en una de sus acepciones (Entre la juventud es frecuente consumir alcohol) pero vejez es individual (*Entre la vejez es frecuente la sordera). De manera que, así como juventud puede ser un conjunto de jóvenes (tal y como explica el diccionario), vejez no puede ser un conjunto de viejos. Igual sucede con niñez.

- Por su significado parecería que tanto ramo como puñado son nombres colectivos; sin embargo, aplicando el método del $\S 8$ se descubre que son individuales (*un numeroso ramo/puñado // *entre el ramo/puñado), si bien pueden actuar como núcleos de sintagmas colectivos (una mosca se paseaba entre el ramo de flores // entre el puñado de garbanzos habia algunas judias).

\subsection{LISTAS DE NOMBRES CLASIFICADOS}

A continuación reseñamos una serie de nombres clasificados siguiendo el método del § 8. En algunos nombres se incluyen dos acepciones identificadas por los subíndices 1 y 2: el 1 corresponde a la acepción de nombre individual y el 2 a la acepción de nombre colectivo. Así por ejemplo, en las oraciones Juan no tiene un pelo de tonto y Juan se tiraba de los pelos se trata de pelor; y en las oraciones Juan tiene mucho pelo y Pedro se ha quedado sin pelo se trata de pelor.

Colectivos heterogéneos porosos acompañamiento, ajuar, alumnado, arsenal, audiencia, auditorio, baraja, caballería, caravana, colectivo, comitiva, conjunto, convoy, coro, correo, correspondencia, cristalería, cubertería, documentación, enjambre, equipaje, escolta, flota, ganado, gente, gentío, guerrilla, jauría, jurado, manada, manifestación, material, mobiliario, muchedumbre, multitud, orquesta, pasaje, pelotón, peonaje, piara, procesión, profesorado, público, reata, rebaño, recua, rehala, séquito, servidumbre, tripulación, tropa, utilería, vajilla.

\section{Colectivos heterogéneos compactos}

accionariado, afición, afluencia, anecdotario, aristocracia, armamento, asamblea, asistencia, asociación, aviación, bagaje, bibliografía, brigada, burguesía, cabildo, camada, candidatura, caserío, casuística, celebración, censo, ciudadanía, clan, clase, claustro, clero, cofradía, colonia, comisión, comité. compañía, comparsa, competencia, comuna, comunidad, concilio, cónclave, confe-

${ }^{28}$ Etimológicamente, archipiélago significa «mar principal» y por antonomasia designa la parte del mar Mediterráneo poblada de islas, entre Grecia y Asia (DUE). 
deración, congregación, congreso, consejería, consejo, consorcio, contingente, convención, corporación, corro, cristiandad, cuadra 2 , cuadrilla, curso, delegación, descendencia, destacamento, dirección, distrito, ejército, electorado, élite, embajada, equipo, escapada, escuadra, escuadrilla, escuadrón, exilio, expedición, facción, facultad, falange, familia, farándula, fauna, filmoteca, fuga, ganadería, gobierno, gremio, grupo, harén, hemeroteca, herencia, hermandad, historial, horda, huelga, información, junta, juventud ${ }_{2}$, legación, lista, marina, matrimonio, militancia, misión, muchachada, nómina, obra, oferta, oposición, orden, orfeón, organización, pandilla, panel, pareja, parentela, parlamento, parroquia, participación, patrimonio, personal, plantilla, pleno, población, policía, polinomio, populacho, producción, profesión, programación, prole, proletariado, promoción, pueblo, redacción, refranero, regimiento, reparto, repertorio, representación, reunión, ronda, sanedrín, santoral, secta, selección, sillería, sínodo, soldadesca, somatén, tertulia, tirada, tribu, tribunal, tuna, universidad, vanguardia, vecindario, vocabulario, zafra.

\section{Colectivos homogéneos porosos}

alboroto, algarabía, algarada, algazara, amasijo, arbolado, arboleda, ${ }^{29}$ arena, asfalto, avena, bambú, barba, barbarie, barro, basura, bigote, bilis, boñiga, bordado, broza, bruma, bullicio, cabello2, caca, café2, cacharrería, calderilla, cañaveral, caos, carbón, carne, carroña, cascajo, cascaruja, cascote 2 , caspa, casquería, ceniza, centeno, cera, césped, chatarra, chusma, cieno, conversación, cortejo, crítica, cuarteto, desorden, encañado, enramada, enredadera, escombro, espesura, espuma, estruendo, excremento, fango, floresta, follaje, fortuna, fronda, fruta2, fuego, fuselaje, grama, grano2, granizo, granza, grasa, grava, gravilla, griterío, guano, harina, hayedo, heno, hierba, hiedra, hojarasca, hollín, humanidad, humareda, humo, jungla, lana, légamo, leña, lío, llovizna, lluvia, lodo, loza, maderaje, maderamen, maleza, marabunta, maraña, masa, mierda, mies, moho, montón, musgo, neblina, nebulosidad, niebla, nieve, oleaje, oscuridad, paisanaje, pajaz, palabrería, paréntesis, pasto, pecina, pedregullo, pelambre, pelambrera, pelo2, pelusa2, penumbra, perilla, piel2, pienso, pinada, pinar, plata, plebe, polvo, porcelana, porquería 2 , quincalla, ramaje, rastrojo, reja, robledal, ropa, ruido, selva, suciedad, tarquín, techumbre, tiniebla, tormenta, tráfico, trigo, tumulto, turbiedad, uva2, vapor, vegetación, ventisca, verdor, vocerío, vorágine, yeso.

\section{Individuales}

abono, actividad, adobe, agenda, aguacero, alameda, alquitrán, alud, aplauso, archipiélago, atlas, azúcar, barniz, batalla, biblioteca, bosque, botonadura, cabellera, cabello1, café, caldo, campanario, cascote 1 , catálogo, cementerio, cerámica, cerveza, chaparrón, chubasco, colección, comida, cooperativa, cordillera, cosecha, crema, cuadra1, delincuencia, demanda, dentadura, dinero, empresa, enciclopedia, enrejado, foresta, fruta 1 , gallinero, goleada, grano, guiso, haz, herbolario, infancia, juventud ${ }_{1}$, laberinto, labor, madeja, manojo, matanza, melena, menaje, mezcla, paja1, pelo, , pelusa, piel 1 , pinacoteca, porquería 1 , puñado, racimo, ramillete, ramo, rosario, serie, sopa, taquillaje, temario, trenza, tropel, uvaı, vejez, vino.

${ }^{29} \mathrm{Si}$ bien el DRAE-2001 define arboleda como sitio poblado de árboles, es decir, apoyándose en un nombre individual (al igual que bosque = sitio poblado de árboles y matas), aparecen en CREA hasta 18 casos en los que figura el sintagma entre la arboleda. Por consiguiente, arboleda es nombre colectivo (a diferencia de bosque) y debe definirse como conjunto de árboles. 


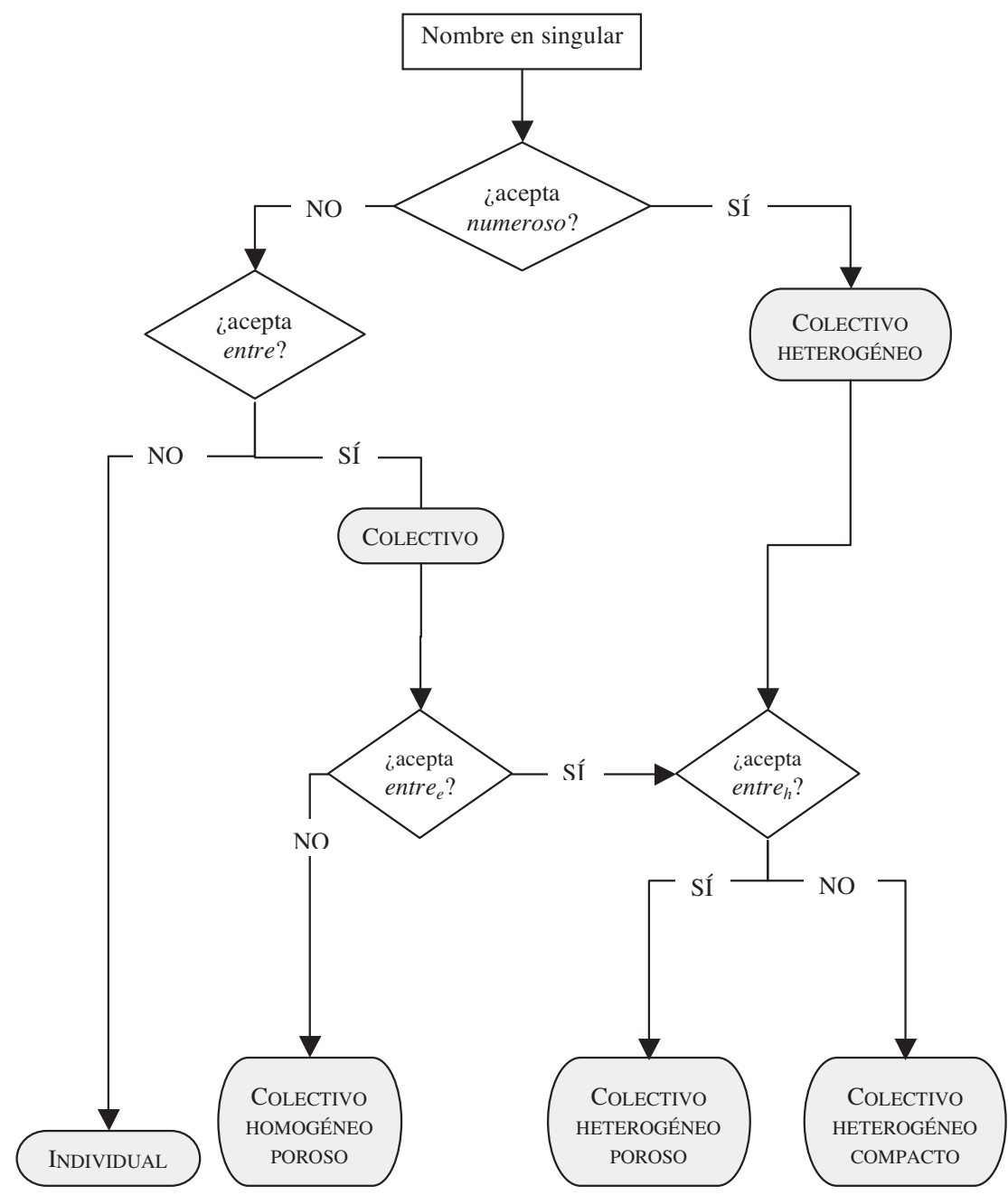

Figura 1. Cómo se clasifica un nombre (cortesía de Victoria Escandell) 


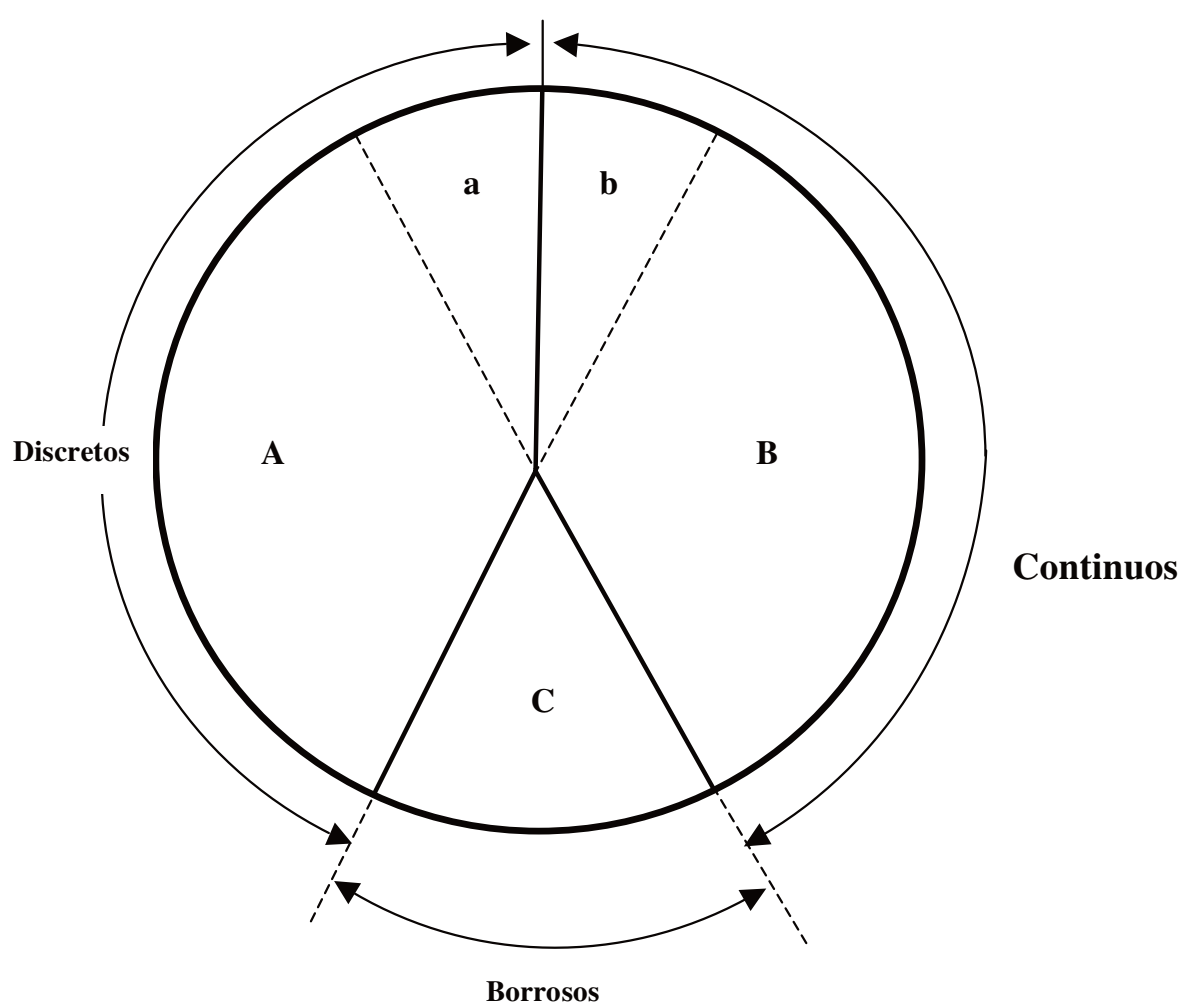

Figura 2. Clases de nombres comunes (cortesía de Victoria Escandell)

$\mathrm{A}+\mathrm{a}=$ nombres contables o discretos (definición 9)

$\mathrm{C}+\mathrm{B}+\mathrm{b}=$ nombres no contables o no discretos

$\mathrm{B}+\mathrm{b}=$ nombres de materia o continuos (definición 10)

$\mathrm{C}+\mathrm{A}+\mathrm{a}=$ nombres discontinuos

$\mathrm{a}+\mathrm{b}=$ nombres discreto-continuos (definición 13)

$\mathrm{a}=$ acepción discreta de los nombres discreto-continuos

$\mathrm{b}=$ acepción continua de los nombres discreto-continuos

$\mathrm{C}=$ nombres borrosos (definición 12) 


\section{REFERENCIAS BIBLIOGRÁFICAS}

Ambadiang, Théophile (1999): «La flexión nominal. Género y número», en I. Bosque y V. Demonte, dirs., Gramática descriptiva de la lengua española, Madrid, Espasa-Calpe, pp. 4843-4913.

BosQue, Ignacio (1999): «El nombre común», en I. Bosque y V. Demonte, dirs., Gramática descriptiva de la lengua española, Madrid, Espasa-Calpe, pp. 3-76.

— dir. (2004): Redes. Diccionario combinatorio del español contemporáneo, Madrid, SM [Redes].

— [Práctico].

Copestake, Ann y Ted Briscoe (1995): «Semi-productive Polysemy and Sense Extension», Journal of Semantics, 12/1, pp. 15-67.

García Meseguer, A. $\left(1996^{2}\right)$ : ¿Es sexista la lengua española? Una investigación sobre el género gramatical, Barcelona, Paidós.

(1989): «Descripción binaria de la lengua: tipología de las palabras con número», en Carlos Martín-Vide, ed., Actas del V Congreso de Lenguajes Naturales y Lenguajes Formales, Barcelona, Universidad de Barcelona, 1, pp. 151-165.

(1993): «De cómo la lengua nos ilustra acerca de la realidad. ¿Qué es un individuo y qué es un colectivo? Rasgos del aspecto nominal», comunicación presentada al XXIII Simposio de la Sociedad Española de Lingüistica, Universidad de Lérida.

GonZÁLEZ Rodríguez, Raquel (2001): «Valores de la preposición entre», Español Actual, 76, pp. 25-39.

Moliner, María (1966-1967): Diccionario de uso del español, Madrid, Gredos [DUE].

Pascual, José Antonio (1996): «La coherencia en los diccionarios de uso», en Esther Forgas, coord., Léxico y diccionarios, Tarragona, Universitat Rovira y Virgili, pp. 167-198.

- (2003): «El laberinto lexicográfico: tres largos paseos por el laberinto de los diccionarios», en Antonia $\mathrm{M}^{\mathrm{a}}$ Medina Guerra, coord., Lexicografía española, Barcelona, Ariel, pp. 353-385.

Real ACAdemia Española (1992²1): Diccionario de la lengua española, Madrid, Espasa-Calpe [DRAE1992].

(200122): Diccionario de la lengua española, Madrid, Espasa-Calpe [DRAE-2001].

SolÉ SolÉ, Elisabet (2002): Els noms col-lectius catalans. Descripció i reconeixement, Tesis doctoral dirigida por María Teresa Cabré, defendida el 8 de julio de 2002 en la Universidad Pompeu Fabra.

WiERZBICKA, Anna (1985): «Oats and Wheats: The Fallacy of Arbitrariness», en J. Haiman, ed., Iconicity in Syntax, Amsterdam, John Benjamins, pp. 311-342.

(1988): «Oats and wheat: mass nouns, iconicity, and human categorization», en The Semantics of Grammar, Amsterdam, John Benjamins, pp. 499-560. 